\title{
Study Comparing the Liver Enzymes in Hypertensive and Normotensive Patients with Type 2 Diabetes
}

\author{
Rishad Ahmed
}

Associate Professor, Dept. of Medicine, KPC Medical College and Hospital, Kolkata, West Bengal, India

\begin{abstract}
Objective: There were few clinical trials which indicate altered liver biochemical findings in diabetic patients, but through investigation to compare the liver enzymes in-between hypertensive and normotensive patients with type 2 diabetes was not evaluated. Thus main objective of current study was to compare the liver enzymes in hypertensive and normotensive patients with type 2 diabetes.
\end{abstract}

Materials and Methods: This was a retrospective observational study conducted in a tertiary medical teaching hospital in Kolkata. Hospital OPD reports and patients clinical case records were used to fetch the required data in a predesigned clinical record pro forma.

Result: Total 180 patients were participated in this observational retrospective trial where $33 \%$ patient were normotensive but having T2DM and $67 \%$ patients were hypertensive with T2DM. There were no statistically significant differences between the study variables among both the groups. However elevated level of GGT, ALT and AST were observed in T2DM normotensive patients as compare to T2DM hypertensive patients. Abnormal liver functions were recorded in patients with uncontrolled diabetes as compared to patients with good control $(\mathrm{p}<0.05)$

Conclusion: The current study concluded that elevated liver enzymes like bilirubin, GGT, SGOT and SGPT were common among diabetes mellitus patients and comparable with patients with hypertensive as well as normotensive patients with diabetes mellitus.

Keywords: Liver enzymes, T2DM, hypertension

\section{INTRODUCTION}

The management of type 2 diabetes mellitus (T2DM) mainly involves maintaining quality of life and preventing or delaying complications, which is possible with glycemic control and cardiovascular risk prevention ${ }^{[1]}$. However, almost half of the T2DM patients achieve less than $7 \%$ haemoglobin A1c (HbA1c) target ${ }^{[2]}$. Patients who have controlled glycemia, blood pressure or cholesterol levels and without smoking are only $14 \%{ }^{[3]}$.

Alteration in liver enzymes levels are one of the most common problems encountered in every day clinical practice. According to American Gastroenterological Association (AGA), 1-4\% of asymptomatic population may have elevated serum liver chemistries ${ }^{[4]}$. Effective lifestyle modifications include complete abstinence from alcohol, control of diabetes and hyperlipidemia, weight loss in overweight patients and stopping or changing potentially hepatotoxic medications and supplements ${ }^{[5]}$. Given the frequencies of the problem, physician should develop an informed approach to the investigation of liver enzyme elevation. Since chronic liver diseases are characterised by long preclinical phase, so early detection of significant liver disease allows therapeutic intervention and life style changes aiming at regression of liver fibrosis. Awareness of the prevalence of determined liver disease in specific populations and of possible hepatic involvement during systematic illness or drug therapies may help the clinicians to 
identify the cause of alteration efficiently. In some cases, however cannot establish a diagnosis at first presentation.

When hypertension is associated with type 2 diabetes it can further aggravate complications include both micro and macro vascular complications ${ }^{[6,7]}$. In the Hong Kong Cardiovascular Risk Factor Prevalence Study, only $56 \%$ of people with hypertension had normal glucose tolerance and only $42 \%$ of people with diabetes had normal blood pressure ${ }^{[8]}$. During long standing diabetes because of increased body fluid volume hypertension occurs ${ }^{[9]}$. A prospective cohort study in the United States reported that as compare to subjects with normal blood pressure, type 2 diabetes mellitus was almost 2.5 times as likely to develop in subjects with hypertension ${ }^{[10]}$.

Liver related diseases recognized in diabetes include cirrhosis, fatty liver diseases, elevated aminotransferase, liver failure and liver carcinoma [9]. Most routinely evaluated liver enzymes in clinical practice are bilirubin, serum aminotransferases and alkaline phosphatase. There were few clinical trials which indicate altered liver biochemical findings in diabetic patients, but through investigation to compare the liver enzymes in-between hypertensive and normotensive patients with type 2 diabetes was not evaluated. Thus main objective of current was to compare the liver enzymes in hypertensive and normotensive patients with type 2 diabetes.

\section{MATERIALS AND METHODS}

This was a retrospective observational study conducted in a tertiary medical teaching hospital in Kolkata. Hospital OPD reports and patients clinical case records were used to fetch the required data in a predesigned clinical record pro forma. Before enrolling to the current study a verbal informed consent was taken from each participant after briefly described the study objective and outline. For the sake of confidentiality and privacy no personal identifiers (names, contact number, mail ID, address and any other private information) was not collected. Data was anonyms and handled confidentially during all phases of research activities. This study was conducted in accordance with the Declaration of Helsinki.

Subjects of both the genders who were more than 18 years of age, having confirmed T2DM with or without hypertension, thoroughly maintaining all clinical records and also willing to participate in this study was initially included in this study. People who were confirmed to have acute hepatitis, history of alcohol intake, having history of any liver disease and medicated with hepatotoxic drugs such as amiodarone and antituberculosis drugs were excluded from the current study.

There were two groups one was the patients who were normotensive but having type 2 diabetes mellitus (T2DM) $(\mathrm{N}=60)$ and in other groups the patients who were hypertensive along with type 2 diabetes mellitus (T2DM) $\quad(\mathrm{N}=120)$. Glycemic control was another criteria to further divided the entire population $(\mathrm{N}=180)$ into three broadly classified groups on the basis of extend of blood glucose control to compare liver function test parameters between these groups, as good control (HbA1c <7\%), poor Control (HbAlc between $7-9 \%$ ) and uncontrolled (HbA1c $>9 \%$ ).

Clinical demographic variables like age, gender, weight, BMI (basal metabolic rate), duration of diabetes, systolic blood pressure (SBP), diastolic blood pressure (DBP) and serological lab reports including glycemic parameters such as fasting plasma glucose (FPG), post prandial glucose (PPG), $\mathrm{HbAlc}$ and liver enzyme like Alkaline Phosphate, Bilirubin Total, GammaGlutamyl Transpeptidase (GGT), alanine aminotransferase (SGPT) and aspartate aminotransferase (SGOT) were tabulated from the participant's clinical records.

By using SPSS ver. 20.0 all statistical analysis was performed in current study. From all the data captured in pre designed format mean and standard 
Rishad Ahmed. Study comparing the liver enzymes in hypertensive and normotensive patients with type 2 diabetes.

deviations were calculated for time varying variables and or categorical variables percentages were calculated for further analysis. $\mathrm{P}$ value $<0.001$ was considered as significant.

\section{RESULT}

Total 180 patients were participated in this observational retrospective trial where $33 \%$ patients were normotensive but having T2DM and $67 \%$ patients were hypertensive with T2DM. Demographic parameters between hypertensive and normotensive diabetes patients were described in table 1. SBP and DBP difference in both the groups were statistically significant. Alkaline Phosphate, GGT, SGOT and SGPT were also higher with statistical significance in patients with uncontrolled diabetes as compared to patients with good control $(\mathrm{p}<0.05)$.

Table 1: Demographic parameters between hypertensive and normotensive diabetes patients

\begin{tabular}{|l|l|l|l|}
\hline Variable & $\begin{array}{l}\text { T2DM without } \\
\text { HTN }(\mathbf{N = 6 0})\end{array}$ & $\begin{array}{l}\text { T2DM with } \\
\text { HTN }(\mathbf{N = 1 2 0})\end{array}$ & $\begin{array}{l}\text { P } \\
\text { value }\end{array}$ \\
\hline Age (year) & $52.24 \pm 12.02$ & $53.77 \pm 11.15$ & 0.437 \\
\hline Male $(\mathrm{N} \%)$ & $26(43 \%)$ & $53(44 \%)$ & 0.251 \\
\hline Weight $(\mathrm{kg})$ & $71.25 \pm 9.32$ & $72.68 \pm 10.27$ & 0.162 \\
\hline BMI $\left(\mathrm{kg} / \mathrm{m}^{2}\right)$ & $24.13 \pm 2.21$ & $25.66 \pm 2.72$ & 0.121 \\
\hline $\begin{array}{l}\text { Duration of } \\
\text { Diabetes } \\
\text { Years) }\end{array}$ & $8.83 \pm 3.64$ & $9.41 \pm 4.23$ & 0.026 \\
\hline SBP $(\mathrm{mmHg})$ & $106.67 \pm 9.98$ & $131.24 \pm 12.37$ & 0.001 \\
\hline DBP $(\mathrm{mmHg})$ & $71.59 \pm 8.46$ & $84.38 \pm 7.82$ & 0.001 \\
\hline FBS(mg/dl) & $136.54 \pm 26.28$ & $140.27 \pm 24.81$ & 0.142 \\
\hline PPG (mg/dl) & $251.24 \pm 41.39$ & $262.71 \pm 42.74$ & 0.014 \\
\hline HbA1c (\%) & $8.6 \pm 1.4$ & $8.2 \pm 1.1$ & 0.022 \\
\hline
\end{tabular}

Comparison of liver function enzymes between hypertensive and normotensive diabetes patients demonstrated in table 2. There were no statistically significant differences between the study variables among both the groups. However elevated level of GGT, ALT and AST were observed in T2DM normotensive patients as compare to T2DM hypertensive patients.

Table 2: Comparison of liver function enzymes between hypertensive and normotensive diabetes patients

\begin{tabular}{|l|l|l|l|}
\hline Variable & $\begin{array}{l}\text { T2DM without } \\
\text { HTN (N=60) }\end{array}$ & $\begin{array}{l}\text { T2DM with } \\
\text { HTN (N=120) }\end{array}$ & $\begin{array}{l}\text { P } \\
\text { value }\end{array}$ \\
\hline $\begin{array}{l}\text { Alkaline } \\
\text { Phosphatase } \\
\text { (IU/L) }\end{array}$ & $131.12 \pm 59.46$ & $111.56 \pm 42.264$ & 0.45 \\
\hline $\begin{array}{l}\text { Bilirubin Total } \\
\text { (mg/dL) }\end{array}$ & $0.62 \pm 0.41$ & $0.68 \pm 0.42$ & 0.76 \\
\hline GGT (U/L) & $61.11 \pm 69.42$ & $41.13 \pm 40.24$ & 0.72 \\
\hline $\begin{array}{l}\text { SGOT or AST } \\
\text { (U/L) }\end{array}$ & $43.17 \pm 64.75$ & $28.56 \pm 17.4$ & 0.16 \\
\hline $\begin{array}{l}\text { SGPT or ALT } \\
\text { (U/L) }\end{array}$ & $62.69 \pm 128.83$ & $34.17 \pm 25.28$ & 0.08 \\
\hline
\end{tabular}

ANOVA with post-hoc multiple comparison Bonferroni test were conducted to analyse the difference of liver enzymes among good control, poor control and uncontrolled groups. Table 3 demonstrated the comparison of liver function test parameters with extend of glycemic control. In the table a denote significant difference between good and poor control, b denote significant difference between good and uncontrolled and $\mathrm{c}$ denote significant difference between uncontrolled and poor control.

Table 3: Showing comparison of liver function test parameters with extend of glycemic control

\begin{tabular}{|l|l|l|l|l|}
\hline Parameters & Good control $(\mathbf{n}=\mathbf{3 6})$ & Poor control $(\mathbf{n}=61)$ & Uncontrolled $(\mathbf{n}=44)$ & P value \\
\hline Alkaline Phosphatase (IU/L) & $111.49 \pm 52.71$ & $99.33 \pm 31.76$ & $131.72 \pm 61.68$ & b,c \\
\hline Bilirubin Total (mg/dL) & $0.71 \pm 0.32$ & $0.49 \pm 0.23$ & $0.66 \pm 0.24$ & NS \\
\hline GGT (U/L) & $37.11 \pm 13.21$ & $44.27 \pm 15.43$ & $52.74 \pm 20.45$ & b,c \\
\hline SGOT or AST (U/L) & $30.17 \pm 13.09$ & $27.31 \pm 13.38$ & $64.38 \pm 41.11$ & b,c \\
\hline SGPT or ALT (U/L) & $32.94 \pm 14.06$ & $38.87 \pm 17.51$ & $118.75 \pm 58.31$ & $\mathrm{~b}, \mathrm{c}$ \\
\hline
\end{tabular}

\section{DISCUSSION}

Few important and relevant information about the impact of diabetes specially uncontrolled or poorly controlled on the liver has unmasked in this present study. Patients who were diagnosed with T2DM for longer duration are also having liver function abnormalities and this was well established by several studies ${ }^{[11-14]}$. In a similar study ${ }^{[15]}$, it was observed that among total T2DM participants $20 \%$ of the patients were found to have elevated level of ALT and AST. Similarly in current study, patients with normotensive T2DM we're having elevated SGOT and SGPT as compare to normal range. In current study it was also observed that none of the pancreatic enzyme levels were higher as 
compare to normal range in hypertensive T2DM group which neglecting the role or effect of hypertension in diabetes patients on liver function enzyme parameters. Even in a previous study [13, 16], when liver enzymes were evaluated between type 1 and type 2 diabetes, SGOT, SGPT, ALP and GGT were significantly high in T2DM subjects but as per as bilirubin values is concern there were no association was observed. Whereas in current study along with GGT, SGOT and SGPT, the direct bilirubin were also higher than the normal range. Munazza et al [17], reported previously that during pregnancy serum bilirubin and liver enzymes such as ALT, AST and ALK were found to be higher in diabetic patients, but current study has not reported such effect of hypertension in diabetes patients. It can be suspected that due to prevailing NAFLD in DM patients liver damages may be induced. To elucidate these facts, BMI were also thoroughly checked in all the participants. But is has observed that in both the groups BMI of DM patients were almost comparable. This observation also in line with previously conducted study by Rashid et al ${ }^{[18]}$.

In this study, abnormal liver functions were recorded in patients with uncontrolled diabetes as compared to patients with good control $(\mathrm{p}<0.05)$, which further strengthen the fact that DM patients are susceptible to liver damages. Marker of hepatocellular injury such as elevated liver enzymes like GGT, SGOT and SGPT also reported by Cho et al ${ }^{[19]}$, in uncontrolled T2DM patients. This study also concluded that raised level of liver enzymes might be the marker of insulin resistance and nonalcoholic steatohepatitis (NASH) as demonstrated previously by Gonem et al ${ }^{[12]}$.

There was few limitation in current study which includes small sample size and single-point assessment of liver functions. To get proper insights into the involvement of liver in DM with or without hypertension more randomised study's should be conducted in future.

\section{CONCLUSION}

The current study concluded that elevated liver enzymes like bilirubin, GGT, SGOT and SGPT were common among diabetes mellitus patients and comparable with patients with hypertensive as well as normotensive patients with diabetes mellitus. Thus, this observation strongly suggests the routine investigation of liver enzymes in both normotensive as well as hypertensive T2DM patients also to assess their long-term follow-up prognosis.

\section{Acknowledgement: None}

\section{Conflict of Interest: None}

\section{Source of Funding: None}

\section{Ethical Approval: Approved}

\section{REFERENCES}

1. Giugliano D, Meier JJ, Esposito K. Heart failure and type 2 diabetes: From cardiovascular outcomes trials, with hope. Diabetes, Obes Metab. 2019;21(5):1081-7.

2. Lipska KJ, Yao X, Herrrin J, et al. Trends in drug utilization, glycemic control and rates of severe hypoglycemia, 2006-2013. Diabetes Care. 2017;40(4):468-75.

3. Ali MK, Bullard KM, Saaddine JB, et al. Achievement of goals in U.S. diabetes care, 1999-2010. N Engl J Med. 2013;368(17): 1613-24.

4. Green RM, Flamm S. AGA technical review on the elevation of liver chemistry tests. Gastroenterology 2002;123:1367-84.

5. Pratt DS, Kalpan MM. Evaluation of abnormal liver-enzyme results in asymptomatic patients. N Engl J Med 2000; 342: 1266-71.

6. Landsberg L, Molitch M. Diabetes and hypertension: pathogenesis, prevention and treatment. Clin Exp Hypertens. 2004;26: 621-628. doi: 10.1081/CEH-200031945.

7. Sowers JR. Insulin resistance and hypertension. Am J Physiol Heart Circ Physiol. 2004;286:H1597-1602. doi: 10.1152/ajpheart.00026.2004.

8. Cheung BM, Wat NM, Tso AW, et al. Association between raised blood pressure and dysglycemia in Hong Kong Chinese. Diabetes Care. 2008;31:1889-1891. 

diabetes.

9. Rizzoni D, Rosei EA. Small artery remodeling in diabetes mellitus. Nutr Metab Cardiovasc Dis. 2009;19:587-92.

10. Gress TW, Nieto FJ, Shahar E, et al. Hypertension and antihypertensive therapy as risk factors for type 2 diabetes mellitus. Atherosclerosis Risk in Communities Study. N Engl J Med. 2000;342:905-912.

11. Harris EH. Elevated Liver function tests in type 2 diabetes. Clinical diabetes 23: 2005: 115.

12. Gonem S. Wall A. De P. Prevalence of abnormal liver function test in patients with diabetes mellitus. Endocrine Abstracts 13: 2007: 157.

13. Salih DH. Study of liver function tests and renal function tests in diabetic type II patients. IOSR Journal of Applied Chemistry (IOSR-JAC) 3(3): 2013: 42-44.

14. Paruk IM. Pirie FJ. et al. High prevalence of abnormal liver enzymes in south African patients with type 2 diabetes mellitus attending a diabetes clinc. JEMDSA 16(1): 2011: 45-49.

15. Ni H, Soe HHK, Htet A. Determinants of Abnormal Liver Function Tests in Diabetes
Patients in Myanmar. International Journal of Diabetes Research 2012; 1(3): 36-41.

16. Choudhary M, Jinger SK, Yogita, Gahlot G, Saxena R.Comparative study of liver function test in type-1 and type-2 diabetes mellitus. Indian J Sci Res 2014; 5 (2): 1437.

17. Munazza B, Raza N, Naureen A, Khan SA, Fatima F, Ayub $M$ et a. Liver Function Tests in Preeclampsia. J Ayub Med Coll Abbottabad 2011;23(4): 3-5.

18. Or Rashid MH, Haque MZ, Rahman MK, et al. Study on Liver Dysfunction in Type 2 Diabetic Patients in Bangladesh. Euroasian J Hepatogastroenterol. 2016;6(1):1-4.

19. Cho NH, Jang HC, Choi SH, Kim HR, Lee HK, Chan JCN et al. Abnormal Liver Function Test Predicts Type 2 Diabetes. Diabetes Care 2007; 30(10): 2566-8.

How to cite this article: Ahmed R. Study comparing the liver enzymes in hypertensive and normotensive patients with type 2 diabetes. International Journal of Research and Review. 2021; 8(7): 207-211. DOI: https://doi.org/10. 52403/ijrr.20210728 